\title{
If you want innovative RE, never ask the users; a formal debate
}

Glinz, M ; Ryan, K ; Maiden, N

DOI: https://doi.org/10.1109/RE.2010.67

Posted at the Zurich Open Repository and Archive, University of Zurich ZORA URL: https://doi.org/10.5167/uzh-43238

Conference or Workshop Item

Originally published at:

Glinz, M; Ryan, K; Maiden, N (2010). If you want innovative RE, never ask the users; a formal debate. In: 18th IEEE International Requirements Engineering Conference (RE'10), Sydney, Australia, 27 September 2010 - 1 October 2010, 388.

DOI: https://doi.org/10.1109/RE.2010.67 


\title{
"If you want innovative RE, never ask the users"
}

\author{
A Formal Debate
}

\author{
Moderator : Kevin Ryan \\ Lero \\ University of Limerick, Ireland \\ Email: kevin.ryan@lero.ie
}

\author{
Proposer : Neil Maiden \\ Centre for Creativity in Professional Practice \\ City University London. UK \\ Email: N.A.M.Maiden@city.ac.uk \\ Opponent : Martin Glinz \\ Department of Informatics \\ University of Zurich, Switzerland \\ Email: glinz@ifi.uzh.ch
}

\begin{abstract}
For the first time at an $\mathrm{RE}$ conference we propose a formal debate on a topic of critical importance to the RE community. The debate format is based on that of the Economist newspaper, in turn derived from the long-standing Oxford Union practices.
\end{abstract}

Keywords-component; debate, innovation, users.

\section{MOTIVATION}

Panel sessions at conferences are often boring, with most if not all the time being taken up by unrelated position statements by panelists. Very little interaction takes place between the panelists and little time is left for questions and comments by the audience. The traditional university debate takes a very different approach. The objective is to sway the opinions of those present by the strength of one's arguments and by the ability to refute those of your opponent.

\section{FORMAT AND PROCESS}

The Oxford Union (http://www.oxford-union.org/home) is a well-known debating society which has evolved a format that aims to combine freedom of expression with ample opportunity to challenge and rebut the opinions of others. In recent years the Economist newspaper has adapted this style to an on-line audience. See, for example, http://www.economist.com/debate/overview/174 which also gives a link to "How and Economist debate works".

At RE'10 we propose to re-adapt the Economist's approach to suit a live debate, while keeping most of its innovations. In particular we will poll the audience at the start of the debate and poll them again at the conclusion, thereby estimating how much influence our speakers have had on the opinions of the audience. The approximate timetable will be:

1. The motion is explained to the audience.

2. They vote on it.

3. The proposer and opponent give opening position statements (maximum 7 mins each)
4. They have the option to then give short rebuttals ( $3 \mathrm{~min}$ each)

5. Everyone can contribute and the two speakers respond briefly as points are made. (30 mins)

6. Proposer and opponent both make closing statements (5 mins each)

7. The audience vote again and we compare the result to that in Step 2.

\section{THE MOTION FOR DECISION}

Finding a suitable motion for an RE conference proved quite demanding. We sought a topic that would be likely to attract and divide both academic and industrial attendees. Of course it was also necessary to have two eager and capable protagonists.

The topic chosen was the statement that: "If you want innovative RE, never ask the users". It is the essence of debate that the protagonists reserve their best points and their angle of attack for the actual debate. However the subject is likely to range across a number of key areas of RE research and practice, including (but, as we always say, not limited to):

- Sources of innovation in RE

- Contextual and situation-specific RE

- The role of domain experts in successful RE

- Ethnographic studies and action research

- Domain-specific RE

Who 'wins' in the final vote is not of prime importance. The overall objective will be served if the audience participates in a lively, provocative and informative debate.

\section{ACKNOWLEDGMENT}

Kevin Ryan acknowledges the support of Science Foundation Ireland under grant 03/CE2/I303_1 to Lero- the Irish Software Engineering Research Centre. 